\title{
Guest Editorial: Special Issue on Wireless Personal Multimedia Communications
}

\author{
Marcelo S. Alencar • Neeli Rashmi Prasad • \\ Valdemar C. Da Rocha Jr. • António Rodrigues • \\ Elvino Sousa
}

Published online: 1 February 2012

C) Springer Science+Business Media, LLC. 2012

The evolution of wireless communications is bringing the world to a different way of experiencing and producing multimedia content. As a result, users are having an increasingly active role in the definition of networks. The chosen topic for the conference that was at the basis of this special issue was thus the pursuit of a really autonomous network infrastructure that will allow the efficient use of the spectrum and reduce energy requirements, exploring new possibilities like cognition and cooperation between users and systems. These developments bring excellent opportunities for the mobile community since new paradigms are needed to support the enormous surge of mobile data in present and future networks.

The series of international symposia on Wireless Personal Multimedia Communications (WPMC) have always been a place where people from all over the world can bring their experiences together to develop knowledge about all aspects related to wireless networks

\footnotetext{
M. S. Alencar

Departamento de Engenharia Elétrica/UFCG, Caixa Postal 10.105, Av. Aprigio Veloso, $\mathrm{n}^{\mathrm{O}} 882$, Bodocongó, Campina Grande, PB, 58.109-970, Brazil

\section{N. R. Prasad}

Center for TeleInFrastruktur (CTIF), Aalborg University (AAU), Niels Jernes Vej 12, 9220 Aalborg Ost, Denmark

V. C. Da Rocha Jr.

Departamento de Eletrônica e Sistemas, Centro de Tecnologia e Geociências, Escola de Engenharia, Universidade Federal de Pernambuco-UFPE, CTG-Av. da Arquitetura, S/N, Cidade Universitária, Recife, PE 50740-550, Brazil

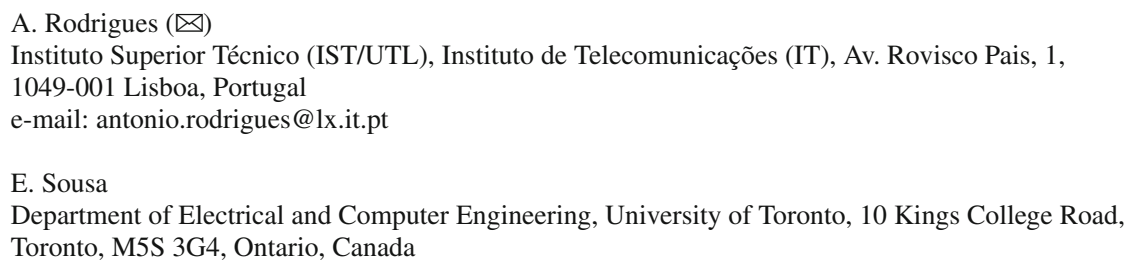


and to discuss the future, bringing the views from academia, regulators, manufacturers and operators, always focusing on the end user.

This special issue was planned to include some of the best papers in a large number of research areas timely when WPMC 2010 was held at Recife, Brazil from October 11-14, 2010.

It contains fourteen papers, which were accepted after peer review. Twenty-two papers have been selected among the excellent papers originally presented at WPMC2010, including awarded papers. The papers were then revised and resubmitted to this special issue.

This issue covers a large number of important research subjects. The initial papers of this issue consider the analysis of multi-branch receivers in different fading scenarios, a turbo multiuser detector, the dynamic switching between single and multiuser MIMO modes and dual-hop non-regenerative OFDM relay system. Then, a second set of papers deal with cognitive and cooperative radio, covering topics like femtocells, spectrum sharing, spectrum sensing, indoor mapping, WSNs and scheduling for interference management. The last four papers consider topics in location, anti-collision algorithms in RFID systems, heading estimation and frequency synthesis in cognitive multi-radio front-ends.

We would like to express our sincere thanks to all the authors who responded the call for papers, the reviewers who provided revision reports for this special issue and, in particular, we would like to thank Anthony Doyle, for his assistance in editing this special issue. 